\title{
地震動の不可知性に対処した建築物の耐震設計 EARTHQUAKE RESISTANT DESIGN APPROACH TO MEET UNKNOWABLENESS OF SEISMIC GROUND MOTIONS
}

\author{
秋山宏* \\ Hiroshi AKIYAMA
}

\begin{abstract}
The number of recorded seismic ground motions is increasing rapidly. However, the statistical data for the structural designers to determine the design ground motion for a specified site remain still far incomplete. While the structural damage may increase as the seismic energy input increases, the structure can remain uncollapsed as far as the sufficient energy absorption capacity is secured. Therefore, it is essential to prepare a sufficient energy absorption capacity for the structure to meet the unknowableness of the seismic input. In this paper, a set of seismic input is considered to cover the unknowableness of the seismic input, and the required strength and the maximum deformation is estimated by applying the energy approach. Framed structures are taken for example and it was found that the required base shear force coefficient can be determined uniquely regardless of the level of seismic input and the structural type(steel structure or reinforced concrete structure).
\end{abstract}

Keywords : Energy approach, Framed structure, Unknowableness of seismic input, Required base shear coefficient エネルギー法, ラーメン構造, 地震入力の不可知性, 必要ベースシア係数

\section{1.はじめに}

最近では大地震の記録の数も多くなってきたが、その数は依然と して限られている。新たな地震が起こる度に新たな事実が明らかと なる。1 地点の起こるべき地震動を的確に予測することは不可能に 近い。一方では、耐震設計は恰も地震動が確定したものとして進め られる。新潟県中越沖地震（2007 年 7 月 16 日）は、間近の東京電 力 (株) 柏崎刈羽原子力発電所の設計用地震動をはるかに超える地震 動をもたらした。しかし、幸いなことに発電所は重大な事故には至 らなかった。何故そうであったのかを解明することは今後の耐震設 計の進歩の為に極めて重要である。本論は通常の建築構造物を対象 として、建物の強度レベル、変形レベルと地震入力レベルの相関性 を群としてとらえることにより、建築物の耐震性の真の様相を明ら かにする 1),2),3)。同一の建物に対して、地震入力レベルが低ければ 建物に生ずる変形は小さくて済む。より大きい入力に対しては変形 は大きくなる。従って、許容変形の幅を大きく採ることができれば、 建物は地震入力の不確定性にも耐えることができることになる。対 象建物はせん断型のラーメン構造とする。

地震時の建物の応答予測はエネルギーの釣合に基づく手法によっ た $^{1)}{ }^{2)}$ 。地震動は、速度応答スペクトルと $V_{D}$ スペクトル（損傷に寄 与寸るエネルギー入力の速度換算值 $V_{D}$ と周期 $T$ との関係）が一致 する単位地震動型 ${ }^{3)}$ とする。

\section{2. 多層ラーメン構造の耐震性評価式 $(P-\delta \text { 効果を無視した場合 })^{1), 2)}$} 多層骨組の地震時のエネルギーの釣合式は次式で与えられる。

$$
W_{e}+W_{p}+W_{h}=E=\frac{M V_{E}^{2}}{2}
$$

ここで、 $W_{e}:$ 弾性振動エネルギー

$W_{p}$ : 累積塑性歪エネルギー

$W_{h}:$ 減衰により吸収されるエネルギー

$E:$ 総エネルギー入力

$V_{E}:$ 総エネルギー入力の速度換算値

$M$ : 総質量

(1)式は次の様に変形できる。

$$
W_{e}+W_{p}=\frac{M V_{E}^{2}}{2} \frac{1}{(1+3 h+1.2 \sqrt{h})^{2}}=\frac{M V_{D}^{2}}{2}
$$

ここで、 $V_{D}$ : 損傷に寄与するエネルギー入力の速度換算值、

$$
h \text { : 減衰定数 }
$$

$W_{e}$ は次式で近似できる。

$$
W_{e}=\frac{M g^{2} T^{2}}{4 \pi^{2}} \cdot \frac{\alpha_{1}^{2}}{2}
$$

ここで、 $g$ : 重力加速度

$T: 1$ 次固有周期

$\alpha_{1}:$ 第 1 層の降伏せん断力係数

$W_{p}$ は次式のように書ける。

$$
W_{p}=\gamma_{1} W_{p 1}
$$

ここで、 $\gamma_{1}$ : 第 1 層の損傷分散係数

$W_{p 1}$ : 第 1 層の累積塑性歪エネルギー

\footnotetext{
* 東京大学 名誉教授 $\cdot$ 工博

Prof. Emeritus, The University of Tokyo, Dr. Eng.
} 
$\gamma_{1}$ は次式で表せる。

$$
\gamma_{1}=\frac{W_{p}}{W_{p 1}}=\frac{\sum_{i} s_{i} p_{i}^{-n}}{s_{1} p_{1}^{-n}}
$$

ここで、 $s_{i}=\left(\frac{\sum_{j=i}^{N} m_{j}}{M}\right)^{2} \bar{\alpha}_{i}^{2} \frac{k_{1}}{k_{i}}$

$$
p_{i}=\frac{\alpha_{i}}{\alpha_{1}} / \bar{\alpha}_{i}
$$

$n:$ 損傷集中指数

$m_{i}: i$ 質点の質量

$\bar{\alpha}_{i}:$ 最適降伏せん断力係数分布

$k_{i}: i$ 層のバネ定数

$\alpha_{i} / \alpha_{1}:$ 降伏せん断力係数分布

$N$ : 建物階数

$n$ の值は次の值をとることができる。

柱降伏型骨組 : $n=12$

梁降伏型骨組 : $n=6$

$\gamma_{1}$ を評価する際の $p_{i}$ の值は次の様にとることができる。

$$
\begin{aligned}
& p_{1}=1.0 \\
& p_{i \neq 1}=p_{d}=1.185-0.0014 \mathrm{~N}
\end{aligned}
$$

ここで、 $p_{d}$ : 設計用の $p_{i \neq 1}$ の設定値

$s_{1}=1.0$ であり次式が得られる。

$$
\gamma_{1}=1+p_{d}^{-n} \sum_{i \neq 1} s_{i}
$$

標準的な骨組として次の值を設定する。

$$
\left.\begin{array}{l}
m_{i}=m \\
\delta_{Y i}=\delta_{Y}
\end{array}\right\}
$$

\section{ここで、 $\delta_{Y_{i}}: i$ 層の降伏層間変形}

標準的な骨組に対して次式が近似的に成り立つ。

$$
\sum_{i} s_{i}=0.36+0.64 N
$$

従って、（7)式は次式に帰着する。

$$
\gamma_{1}=1+0.64(N-1) p_{d}^{-n}
$$

復元力特性が図 1 に示寸完全弾塑性型の場合、 $W_{p 1}$ は次式で表せ る。

$$
W_{p 1}=\frac{M g^{2} T^{2}}{4 \pi^{2}} \cdot \frac{\alpha_{1}^{2} \gamma_{1} \eta_{1}}{\kappa_{1}}
$$

ここで、 $\kappa_{1}=k_{1} / k_{e q}$

$\eta_{1}$ : 第 1 層の累積塑性変形倍率

$k_{e q}=\frac{4 \pi^{2} M}{T^{2}}:$ 等価バネ定数

$\eta_{1}$ は第 1 層の塑性変形倍率 $\mu_{1}$ （図 1 参照）を用いて次式で表さ れる。

$$
\eta_{1}=a_{d} \mu_{1}
$$

ここで、 $a_{d}$ : 復元力特性によって定まる定数

標準的な骨組では $\kappa_{1}$ は次式で近似できる。

$$
\kappa_{1}=0.48+0.52 \mathrm{~N}
$$

(3)、（4) 式を(2)式に代入すれば次式が得られる。

$$
\frac{M g^{2} T^{2}}{4 \pi^{2}} \alpha_{1}^{2}\left(\frac{1}{2}+\frac{a_{d} \mu_{1} \gamma_{1}}{\kappa_{1}}\right)=\frac{M V_{E}^{2}}{2} \frac{1}{(1+3 h+1.2 \sqrt{h})^{2}}
$$

(14)式より次式が得られる。

$$
\alpha_{1}=\frac{1}{\sqrt{1+\frac{2 a_{d} \mu_{1} \gamma_{1}}{\kappa_{1}}}} \frac{2 \pi}{g T} \frac{V_{E}}{(1+3 h+1.2 \sqrt{h})}
$$

次に、エネルギースペクトルの形態として図 2 に示すものを想定 する。即ち、

$$
\begin{array}{ll}
T \leq T_{G} \text { の場合 } & V_{E}=\frac{T V_{E m}}{T_{G}} \\
T>T_{G} \text { の場合 } & V_{E}=V_{E m}
\end{array}
$$

ここで、 $T_{G}$ : 限界周期

$$
V_{E m}: V_{E} \text { の最大值 }
$$

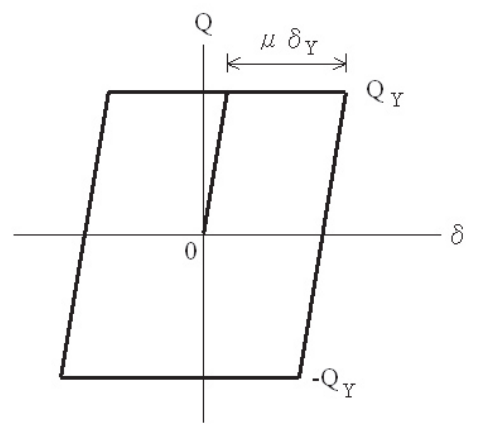

図1 完全弾塑性型復元力特性

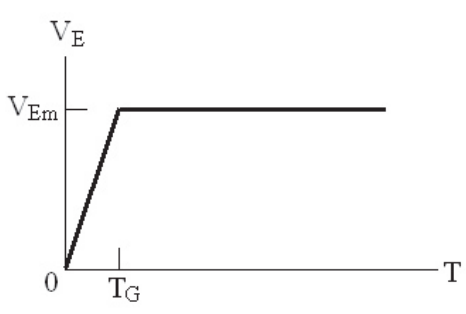

図 2 エネルギースペクトル

(15)式を（16）式の各線分に適用すれば、 2 つの $\alpha_{1}\left({ }_{1} \alpha_{1},{ }_{2} \alpha_{1}\right)$ が求まる。

$$
\begin{aligned}
& T \leq T_{G} \text { の場合 } \\
& \alpha_{1}={ }_{1} \alpha_{1}=\frac{1}{\sqrt{1+\frac{2 a_{d} \mu_{1} \gamma_{1}}{\kappa_{1}}}} \cdot \frac{2 \pi}{g T_{G}} \frac{V_{E m}}{(1+3 h+1.2 \sqrt{h})} \\
& T>T_{G} \text { の場合 } \\
& \alpha_{1}={ }_{2} \alpha_{1}=\frac{1}{\sqrt{1+\frac{2 a_{d} \mu_{1} \gamma_{1}}{\kappa_{1}}}} \cdot \frac{2 \pi}{g T} \frac{V_{E m}}{(1+3 h+1.2 \sqrt{h})}
\end{aligned}
$$

但し、(17)式の第 2 式中の $T$ は次式で表される。

$$
T=2 \pi \sqrt{\frac{M}{k_{e q}}}=2 \pi \sqrt{\frac{\delta_{Y} \kappa_{1}}{\alpha_{1} g}}
$$


（18）式を(17) 式の第 2 式へ代入して $\alpha_{1}$ について解けば次式が得 られる。

$$
\begin{gathered}
{ }_{2} \alpha_{1}=\frac{1}{\kappa_{1}+2 a_{d} \mu_{1} \gamma_{1}} \cdot \frac{V_{E m}^{2}}{\delta_{Y} g} \frac{1}{(1+3 h+1.2 \sqrt{h})^{2}} \\
\text { 真の } \alpha_{1} \text { は次式によって与えられる。 } \\
\alpha_{1}=\operatorname{Min}\left\{{ }_{1} \alpha_{1},{ }_{2} \alpha_{1}\right\}
\end{gathered}
$$

\section{3. 多層ラーメン構造の耐震性評価式 $(P-\delta \text { 効果を考慮した場合 })^{4)}$}

図 3 に示す骨組第 1 層における $P-\delta$ 効果は水平加力下の層間変 位 $\delta_{1}$ と層に加わる総重量 $W$ によってもたらされる付加せん断力 $\Delta Q$ としてとらえることができる。 $\Delta Q$ は柱頭、柱脚をピン支持と すれば次の值となる。

$$
\Delta Q=-\frac{W \delta_{1}}{H}=k_{P \delta 1} \delta_{1}
$$

ここで、 $H$ : 階高、 $W$ : 総重量

$k_{P \delta 1}: P-\delta$ 効果による負のバネ定数

第 1 層のバネ定数 $k_{1}$ に対する $k_{P \delta 1}$ の比率 $k_{P \delta 1}^{\prime}$ は次式で表される。

$$
k_{P \delta 1}^{\prime}=\frac{k_{P \delta 1}}{k_{1}}=-\frac{\theta_{Y 1}}{\alpha_{1}}
$$

ここで、 $\theta_{Y 1}=\frac{\delta_{Y}}{H}:$ 第 1 層の降伏変形角

第 1 層の単調加力下の荷重変形関係は $P-\delta$ 効果の有無により図 4 に示寸様に変化する。 $0-\mathrm{A}-\mathrm{B}$ が $P-\delta$ 効果が無い場合で、0 $-\mathrm{A},-\mathrm{U}$ が $P-\delta$ 効果がある場合である。 $P-\delta$ 効果の下では変形 が一方向に偏り、図 4 中の $\triangle O A A^{\prime} U$ で示される面積によりエネルギ 一吸収量が限界づけられるとすれば、第 1 層のエネルギー吸収量の 上限值 ${ }_{u} W_{p 1}$ は次の值となる。

$$
{ }_{u} W_{p 1}=\frac{Q_{Y 1} \delta_{Y}\left(1-\left|k_{P \delta 1}^{\prime}\right|\right)}{2\left|k_{P \delta 1}^{\prime}\right|}
$$

従って、P- $\delta$ 効果によって限界づけられる第 1 層の累積塑性変形 倍率 $\eta_{u 1}$ は次の值となる。

$$
\eta_{u 1}=\frac{1-\left|k_{P \delta 1}^{\prime}\right|}{2\left|k_{P \delta 1}^{\prime}\right|}
$$

また、 $P-\delta$ 効果により、一般に第 1 層のエネルギー吸収量は次 式で示される様に減少する。

$$
\frac{W_{p 1}}{{ }_{u} W_{p 1}}=0.367\left|k_{P S 1}^{\prime}\right|^{-0.2}
$$

（22）式より、（25）式は次式のように表現できる。

$$
\frac{W_{p 1}}{{ }_{u} W_{p 1}}=0.367 \theta_{Y 1}^{-0.2} \alpha_{1}^{0.2}
$$

(26) 式のエネルギー吸収低下率が (2) 式の $W_{p}$ のみならず $W_{e}$ にも 及ぶものと仮定すれば、 $P-\delta$ 効果を考慮した場合のエネルギーの 釣合式は(14) 式に代えて次式となる。

$\frac{M g^{2} T^{2}}{4 \pi^{2}} \alpha_{1}^{2.2} \cdot 0.367 \theta_{Y}^{-0.2}\left(\frac{1}{2}+\frac{a_{d} \mu_{1} \gamma_{1}}{\kappa_{1}}\right)=\frac{M V_{E}^{2}}{2} \frac{1}{(1+3 h+1.2 \sqrt{h})^{2}}$

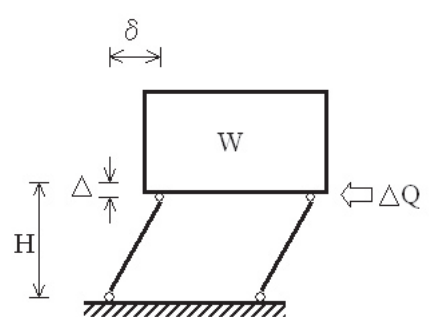

図 $3 \quad P-\delta$ 効果

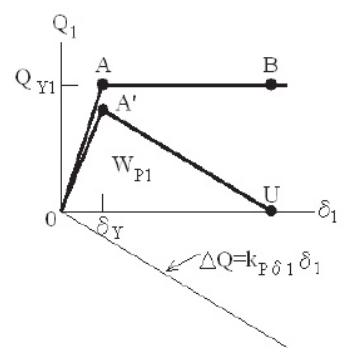

図 4 荷重変形関係
(27) 式を適用することにより、 $P-\delta$ 効果を考慮した場合の ${ }_{1} \alpha_{1},{ }_{2} \alpha_{1}$ は次の值となる。

$$
\left.\begin{array}{l}
{ }_{1} \alpha_{1}^{\prime}=\left({ }_{1} \alpha_{1} \cdot \frac{\theta_{Y}^{0.1}}{\sqrt{0.367}}\right)^{\frac{1}{1.1}} \\
{ }_{2} \alpha_{1}^{\prime}=\left({ }_{2} \alpha_{1} \cdot \frac{\theta_{Y}^{0.2}}{0.367}\right)^{\frac{1}{1.2}}
\end{array}\right\}
$$

ここで、 ${ }_{1} \alpha_{1}^{\prime}: P-\delta$ 効果を考慮した場合の ${ }_{1} \alpha_{1}$

${ }_{2} \alpha_{1}^{\prime}: P-\delta$ 効果を考慮した場合の ${ }_{2} \alpha_{1}$

${ }_{1} \alpha_{1}: P-\delta$ 効果を無視した場合の ${ }_{1} \alpha_{1}$ ${ }_{2} \alpha_{1}: P-\delta$ 効果を無視した場合の ${ }_{2} \alpha_{1}$

最終的に $P-\delta$ 効果を考慮して得られる $\alpha_{1}$ は次式により定まる。

$$
\alpha_{1}=\operatorname{Min}\left\{{ }_{1} \alpha_{1}^{\prime},{ }_{2} \alpha_{1}^{\prime}\right\}
$$

\section{4. 有効周期 5)}

地震入力を評価する (16) 式の第 1 式において、 $T$ は建物の 1 次固 有周期 $T_{o}$ を用いたが、実際には有効周期を用いるべきである。有効 周期は形式的に次式のように書ける。

$$
T_{e}=\frac{T_{o}+T_{m}}{2}=a T_{o}
$$

ここで、 $T_{e}$ : 有効周期、 $T_{m}$ : 最長周期、 $a$ : 周期の修正係数

1 層骨組の場合、 $a$ の值は復元力特性に従って定まる。 $T_{m}$ は塑 性化による最長周期で一般には図 5 に示される割線剛性に対応する 周期 $T_{s}$ に修正係数 $a_{T}$ を乗じて表現される。

$$
T_{m}=a_{T} T_{s}
$$

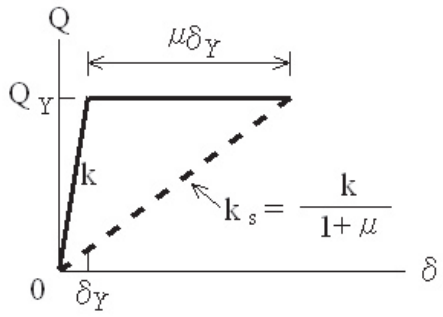

図 5 割線剛性

復元力特性の第 2 勾配が $\delta$ 軸に平行な場合 $T_{s}$ は次の值となる。

$$
T_{s}=\sqrt{1+\mu} T_{o}
$$

$a$ の值は次の值に帰着する。

$$
a=\frac{1+a_{T} \sqrt{1+\mu}}{2}
$$

多層骨組の場合には $\mu$ の值として $\mu_{i}$ の平均值を用いることがで 
き、 $\mu_{i}$ の平均值 $\bar{\mu}_{i}$ は次式で与えられる。

$$
\mu=\bar{\mu}_{i}=\frac{\mu_{1} \gamma_{1}}{\sum_{i} s_{i}}
$$

\section{5. 例題}

例題として鋼構造ラーメン構造、鉄筋コンクリート造ラーメン構 造をとりあげる。地震入力としては図 6 に示す広範なエネルギース ペクトルをとり上げる。図 6 に示すエネルギースペクトルは兵庫県 南部地震の記録、長周期地震動に対する最近の予測波 ${ }^{6)}$ を概ね包絡 するものとして設定されている。ローマ数字 I 〜 V は地震入力のレ ベルを表す。

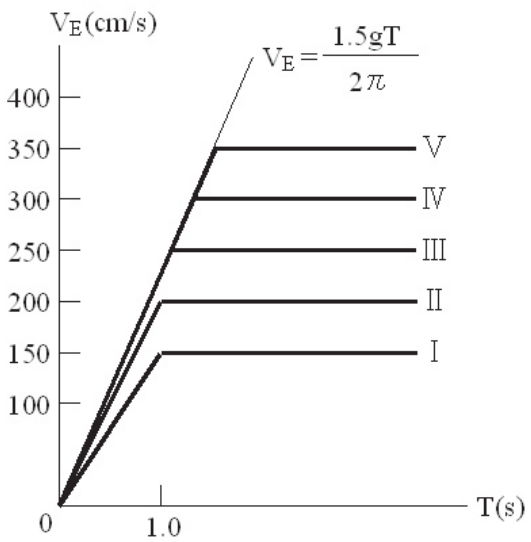

図 6 エネルギースペクトル

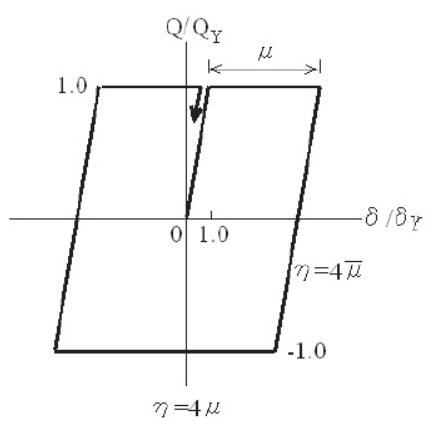

(a) 鋼構造

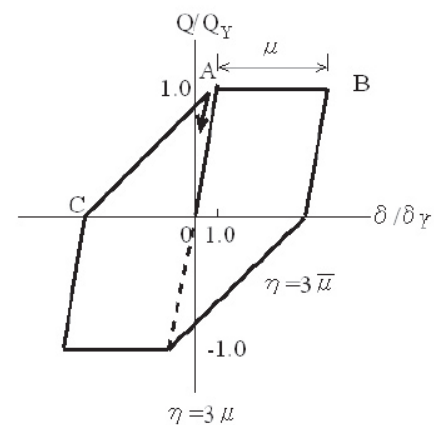

(b) 鉄筋コンクリート構造
図 7 復元力特性

鋼構造、鉄筋コンクリート構造の概要は表 1 に示してある。復元 力特性は 1 ループに相当するものが図 7 に示してある。鋼構造は完 全弾塑性型と見なし、 $a_{d}$ の值は 4.0 を採ることができる。鉄筋コン クリート構造の場合、0-A間は直線としコンクリートの曲げ亀裂 発生に伴うエネルギー吸収を無視した。この為に減衰定数は 0.05 と している。また、履歴ループは C 点に到達した後 $\mathrm{B}$ 点を指向するも のであるが、A 点に向かうもので近似し、 $a_{d}$ の值 $(\eta / \mu)$ は 3.0 と した。両構造共に梁降伏型とし、 $\delta_{Y} 、 H$ は共通の值を用いた。地 震入力が増大寸れば塑性変形は増大する。 $\alpha_{1}$ が同一であれば(19)式 に従えば $\mu_{1}$ と $V_{E}^{2}$ はほぼ比例すると考えられる。このことから、 $\mu_{1}$ の設定值は $V_{E m}^{2}$ に比例的に設定した。 $\mu_{1}$ の設定值は次式で表せるも のを採用した。

$$
\mu_{1}=\mu_{0} N^{-0.2}
$$

$\mu_{0}$ の值は $V_{E m}^{2}$ にほぼ比例する值として表 2 に示す值とする。

表 1 構造概要

\begin{tabular}{c|c|c}
\hline & 鋼構造 & 鉄筋コンクリート構造 \\
\hline$h$ & 0.02 & 0.05 \\
\hline$a_{d}$ & 4.0 & 3.0 \\
\hline$a_{T}$ & $\left(1+\frac{\mu}{8}\right) / \sqrt{1+\mu}$ & 1.0 \\
\hline$a$ & $1+\frac{\mu}{16}$ & $\frac{1+\sqrt{1+\mu}}{2}$ \\
\hline$\delta_{Y}(\mathrm{~cm})$ & \multicolumn{2}{c}{2.5} \\
\hline$H(\mathrm{~cm})$ & 400 \\
\hline
\end{tabular}

表 2 地震入力レベルと $\mu_{0}$ の対応

\begin{tabular}{c|c|c|c|c|c}
\hline & I & II & III & IV & V \\
\hline$\mu_{0}$ & 1.5 & 2.5 & 4.0 & 6.0 & 8.0 \\
\hline
\end{tabular}

建物の階数が増すと建物の重要性は増すと考えることができる。 その理由は次のようなものである。

1）1棟の被害の総量が大きくなる

2）周辺に与える被害の波及効果が増大する

3）被害の修復が困難になる

4） $P-\delta$ 効果の影響が大きくなる

この様な理由で、 $N$ が増大するにつれて損傷度を低減させること は安全率を高める上で有効であり、(35) 式に示す様に、 $N$ の増大が $\mu_{1}$ の設定值を減少させる関数を採用する。建物の第 1 層の残留変形 $\delta_{r}$ は次式で近似的に表せる ${ }^{2)}$ 。

$$
\delta_{r}=\frac{\delta_{p m 1}}{2}=\frac{\delta_{Y} \mu_{1}}{2}
$$

ここで、 $\delta_{p m 1}$ : 第 1 層の最大層間変形

図 8 には $(35)$ 式の $\mu_{1}$ の設定に対応した残留変形と $N$ との関係を 示す。

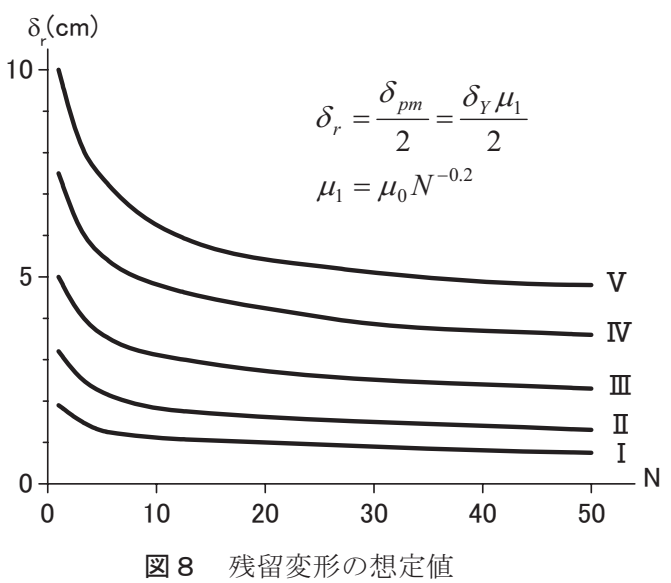

(29) 式により得られた第 1 層の降伏せん断力係数は図 9 に示され ている。

$P-\delta$ 効果により限界づけられる $\eta_{1}$ は $(24)$ 式で与えられる。この 
值を最大塑性変形倍率に換算した值 $\bar{\mu}_{\mu}$ は次式で与えられる。

$$
\bar{\mu}_{u}=\frac{\eta_{u}}{a_{d}}=\frac{1-\left|k_{P \delta}^{\prime}\right|}{2 a_{d}\left|k_{P \delta}^{\prime}\right|}
$$

一般に $\left|k_{P \delta}^{\prime}\right| \leq 0.1$ となり、(37) 式は安全側に次式で近似できる。

$$
\bar{\mu}_{u}=\frac{0.9}{2 a_{d}\left|k_{P \delta}^{\prime}\right|}=\frac{0.9}{2 a_{d}} \frac{\alpha_{1}}{\theta_{Y 1}}
$$

図 9 に示される $\alpha_{1}$ を(38) 式に代入して得られる $\bar{\mu}_{u}$ が設定された $\mu_{1}$ より小さければ、 $P-\delta$ 効果により $\mu_{1}$ が限界づけられることに なる。この場合には、エネルギースペクトルの第 2 分岐 $\left(V_{E}=V_{E m}\right)$ に 対応する ${ }_{2} \alpha_{1}^{\prime}$ に適用すべき $\mu_{1}$ を(38) 式で与えられる $\bar{\mu}_{u}$ に代えるこ とにより ${ }_{2} \alpha_{1}^{\prime}$ 无求められる。（27）、（28）式により ${ }_{2} \alpha_{1}^{\prime}$ は次式で与え られる。

$$
{ }_{2} \alpha_{1}^{1.2}=\frac{\theta_{Y}^{0.2}}{0.367}\left[\frac{V_{E m}^{2}}{g \delta_{Y 1} \kappa_{1}} \frac{1}{1+\frac{2 \gamma_{1} a_{d} \mu_{1}}{\kappa_{1}}} \frac{1}{(1+3 h+1.2 \sqrt{h})^{2}}\right]
$$

(39) 式より得られる ${ }_{2} \alpha_{1}^{\prime}$ は $P-\delta$ 効果によって限界づけられる $\alpha_{1}$ の下限值である。この值を $\alpha_{u}$ とする。 $\alpha_{u}$ と $V_{E m}$ との関係を建物階 数 $N$ に着目して示したものが図 10 の実線である。

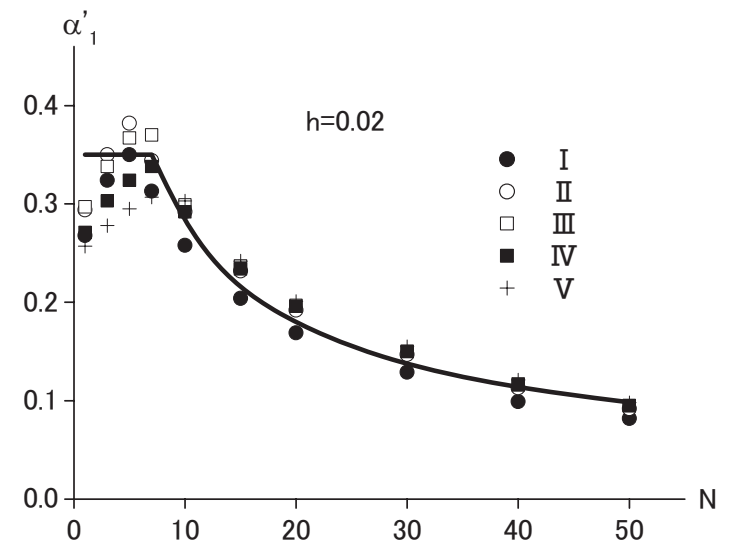

(a) 鋼構造

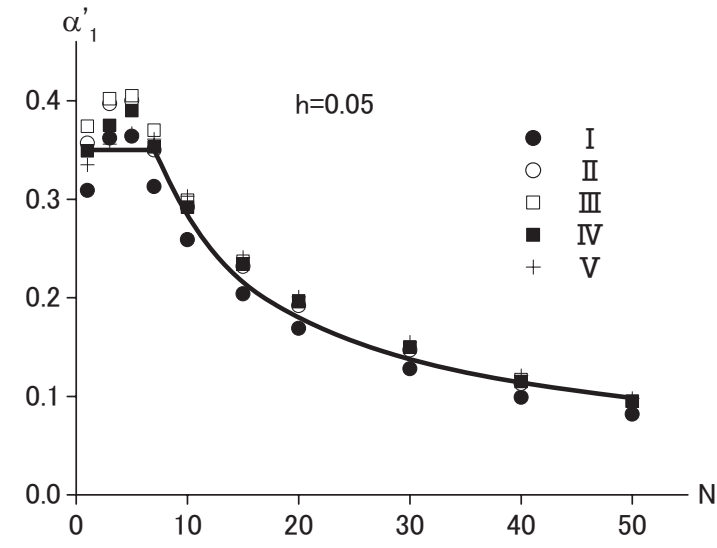

(b) 鉄筋コンクリート構造

図 $9 \alpha_{1}-N$ 関係
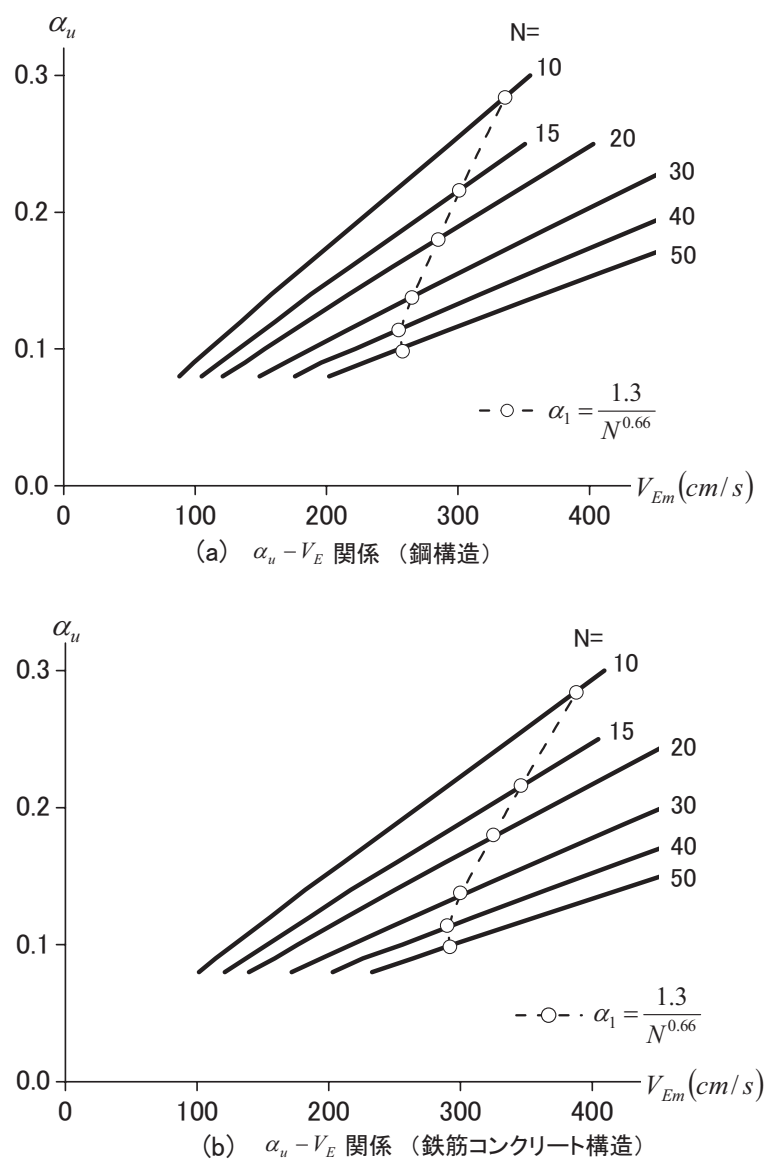

図 $10 \alpha_{u}-V_{E m}$ 関係

図 9 において、 $\alpha_{1}-N$ 関係は鋼構造と鉄筋コンクリート構造に おいて大差ない。 $N<8$ の領域では若干鉄筋コンクリート構造の方 が必要とされている $\alpha_{1}$ が大きい。このことは、鉄筋コンクリート構 造の方が塑性化により有効周期が伸び短周期領域で地震入力が大き くなることに起因する。

鉄筋コンクリート構造では減衰が大きいが、鋼構造に比べて $a_{d}$ が 小さく塑性歪エネルギー吸収における効率が低い。この様なことか ら所要の $\alpha_{1}$ が両者でほぼ等しいものになると考えられる。 $\alpha_{1}$ の值 はほぼ次式で代表できる。

$$
\left.\begin{array}{lll}
N \leq 7 & \text { で } & \alpha_{1}=0.35 \\
N \geq 8 & \text { で } \quad \alpha_{1}=\frac{1.3}{N^{0.66}}
\end{array}\right\}
$$

図 10 上に(40)式の関係を破線で示す。各階数 $N$ に対応する○印 で示す $\left(\alpha_{u}, V_{E m}\right)$ より右側の実線が (38) 式の $\bar{\mu}_{u}$ により支配される 領域となる。従って、○印が(40)式の適用限界を示すことになる。

\section{5. 結語}

地震入力レベルの大きな変動に対処する為には建物の損傷度 (許 容変形) の幅を広く設定することが有効であることを明らかにした。 建築の主要形式であるラーメン構造をとり上げ、ラーメン構造が、 階数毎に一定の強度を付与寸ることによって、広い地震入力の変動 幅に対して抵抗し得ることを示した。この階数毎の所要強度は鋼構 造、鉄筋コンクリート構造と云った材料種別にも無関係であること 
も明らかとなった。所要強度を第 1 層の降伏せん断力係数で表現す れば次のようになる。

$$
\begin{array}{lll}
N \leq 7 & \text { で } & \alpha_{1}=0.35 \\
N \geq 8 & \text { で } & \alpha_{1}=\frac{1.3}{N^{0.66}}
\end{array}
$$

(41) 式の適用範囲はおおむね $V_{E m} \leq 250 \mathrm{~cm} / \mathrm{s}$ である。 $V_{E m}>250 \mathrm{~cm} / \mathrm{s}$ では図 10 に示される $P-\delta$ 効果の影響を考慮した○ 印より右側の実線となる。

$N \leq 7$ はほぼ旧建築基準法の $31 \mathrm{~m}$ の高さ制限に対応する。上記の $\alpha_{1}$ は終局強度設計における画一的な強度規定に対応寸るものであ る。上記の強度で設計された建物は、変形能力が保証されれば、 $V_{E}$ で倍以上の地震に対しても耐震性を発揮し得るものである。

一方、免震構造、制振構造は、損傷度の軽減を目標とした構造で あり、損傷度の幅は狭く、それに対応して抵抗できる地震入力レベ
ルの幅も狭く、その点では一般の耐震構造の方が免震構造や制振構 造に優っていると云うことができよう。

\section{参考文献}

1) 秋山 宏：建築物の耐震極限設計, 東京大学出版会, 1980（第 1 版）, 1987 (第 2 版)

2) 秋山 宏: エネルギーの釣合に基づく建築物の耐震設計, 技報堂出版, 1999 3) 秋山 宏, 北村春幸 : エネルギースペクトルと速度応答スペクトルの対応, 日本建築学会構造系論文集 第 608 号 pp. 37-43,2006.10

4) 秋山 宏: $P-\delta$ 効果を考慮したせん断型多層骨組の耐震設計, 日本建築学 会構造系論文集 第 617 号 pp. 87-94, 2007.7

5) 秋山 宏: 非線形性の強い構造物の有効周期, 日本建築学会構造系論文集 第 621 号 pp. 17-23, 2007.11

6) 日本建築学会 : 長周期地震動々建築物の耐震性, 丸善, 2007. 12

(2009年 4 月 8 日原稿受理, 2009 年 6 月 5 日採用決定) 